\title{
Correction to: Speed and directedness predict colonization sequence post-disturbance
}

\author{
John V. Gatto ${ }^{1,2}$ (D) Joel C. Trexler ${ }^{1}$
}

Published online: 14 July 2020

○) Springer-Verlag GmbH Germany, part of Springer Nature 2020

\section{Correction to: Oecologia}

https://doi.org/10.1007/s00442-020-04689-7

Authors would like to update the incorrect version of Fig. 4. The axes were not labeled correctly in panels $\mathrm{A}$ and $\mathrm{B}$. The correct Fig. 4 appears below. Panel A is corrected to show increasing speed and directedness and panel B is corrected to show decreasing speed and directedness.

The original article can be found online at https://doi.org/10.1007/ s00442-020-04689-7.

John V. Gatto

jvgatto89@gmail.com

1 Department of Biological Science, Florida International University, 3000 NE 151st Street, North Miami, FL 33181, USA

2 Great Rivers Field Station, Illinois Natural History Survey, University of Illinois Urbana-Champaign, 918 Union St, Alton, IL 62002, USA 


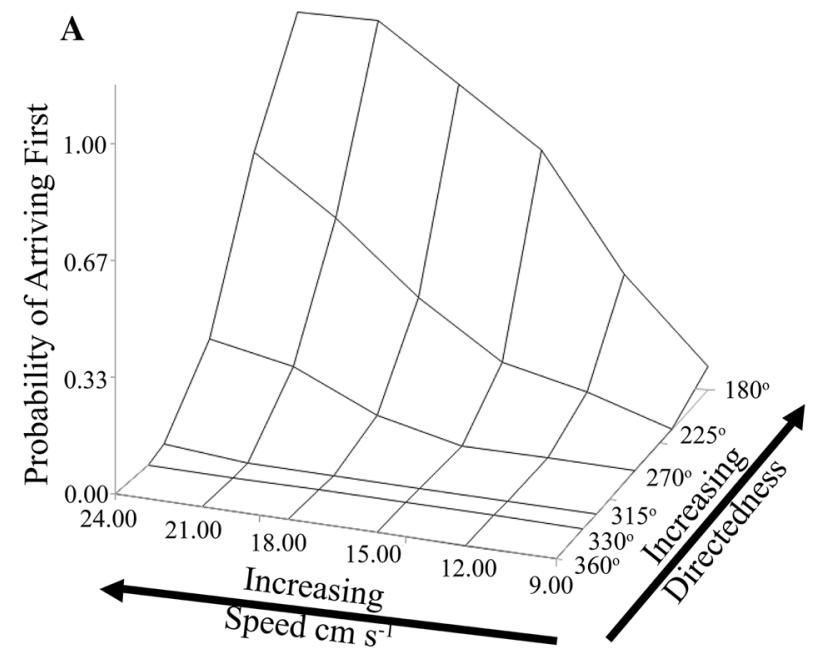

B

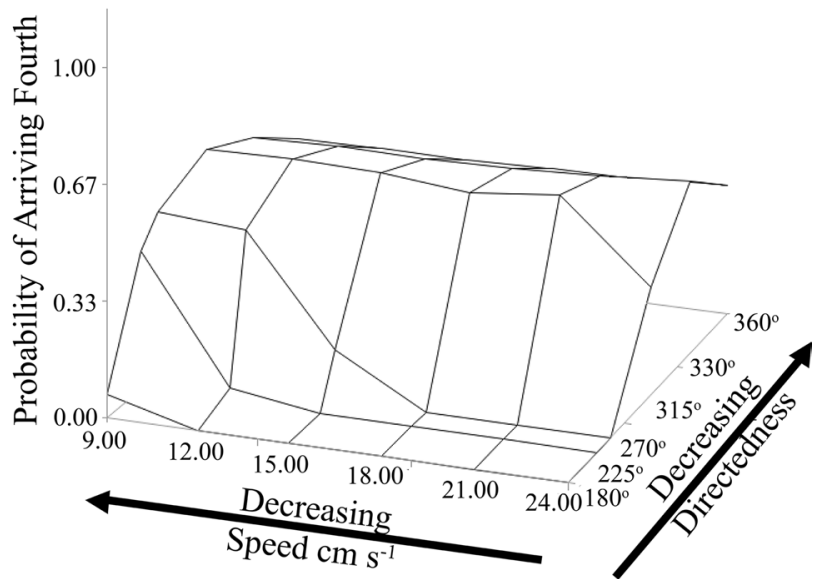

C

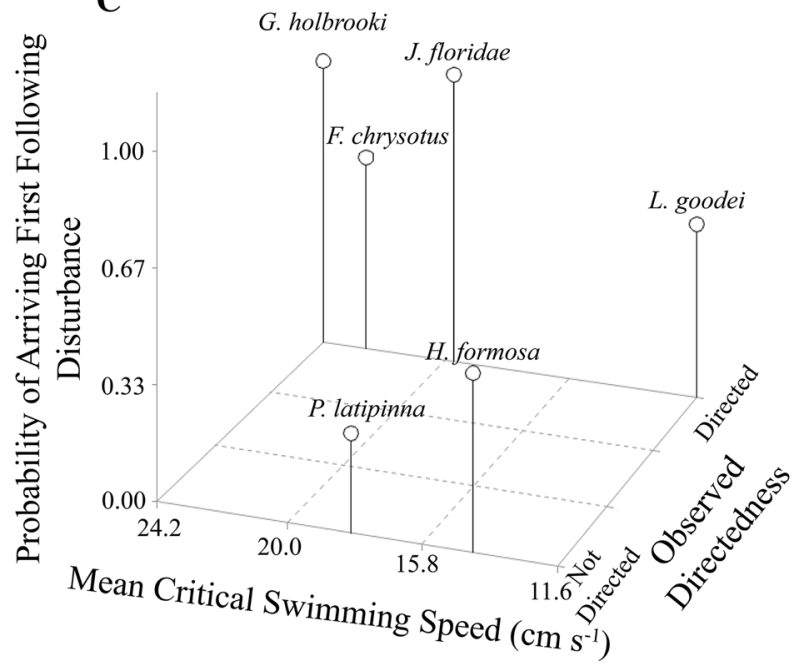

Fig. 4 Three-dimensional plot describing arrival probabilities based on speed/directedness combinations from the ABM's for a arriving first and $\mathbf{b}$ arriving fourth. The horizontal axes for Fig. $4 \mathrm{~b}$ were rotated $180^{\circ}$ to highlight differences between fast/directed and slow/ non-directed. Arrival probabilities were calculated based on arrival time at the end of each simulated run. $\mathbf{c}$ Observed field probabilities

of arriving first based on a species estimated $U_{\mathrm{CRIT}}$ and observed directedness in the field. $U_{\text {CRIT }}$ was calculated from endurance tests. Directed species were assigned a value of 1 and non-directed species a value of 0 . Observed field probabilities were calculated based on species' arrival times following re-inundation of the habitat (Table 4) 